Military Technical College Kobry El-Kobbah, Cairo, Egypt

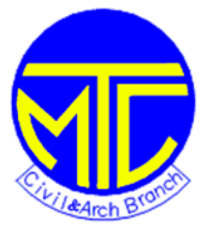

\section{$8^{\text {th }}$ International Conference on Civil and Architecture Engineering}

ICCAE-8-2010

\title{
Field Testing of Blast - Induced Ground Excitation due to Explosion in Rock Mass
}

\author{
Hazem A. Hasan , Adel M. Belal ${ }^{* *}$
}

\section{$\underline{\text { Abstract }}$}

This paper presents results of an experimental investigation to study the effect of blast wave propagation in rock mass due to explosions. The aim of this study is to observe the dynamic response of rock mass under blasting vibrations and the effect of different geological conditions of rock mass on the wave propagation of the explosion. A series of field experiments were conducted including different variables such as, charge weight, horizontal charge-target distance and target location below the ground surface.

The main results show that the geological conditions of rock mass such as, joints, fractures, cracks and cavities have a direct effect on blast wave propagation and the value of pressure on rock mass due to explosion. The effect of rock joints on blast wave propagation can be used to assess the quality of rock mass and hence can be utilized to protect underground structures from blast-induced damage.

\section{Keywords:}

Shock wave, explosion, rock mass, blast waves.

\section{Introduction}

Blast-induced ground excitation has a great influence on the construction of fortified structures. Understanding the dynamic response and damage characteristics of rock mass due to blast ground motions is essential for safe and economic design of underground structures [1].

\footnotetext{
* Ph.D. Candidate, Civil Eng., Department, Military Technical College, Egypt. Assoc. Prof., Civil Eng., Department, Military Technical College, Egypt.
} 
It is well known that the rock fragmentation by blasting is a dynamic fracture process. In rock blasting the stress waves have significant contribution to damage and fragmentation. The propagation, reflection and interaction of the stress waves result in crushing, spalling and fragmentation of rock material [2]. Different degrees of fragmentation will be produced when two different rock masses subjected to identical blast geometry and energy input from explosives. This is because the rock masses have inherently different resistance to fragmentation by blasting because the two rock masses have a different ease with which they can be fragmented by blasting. This property is referred as the "blastability" of a rock mass. It appears to be a kind of intrinsic property like the hardness of a rock mass and it is uncontrollable [3].

A natural rock mass is usually not homogeneous, and it is full of various weak planes with different structures and different geological conditions, such as fractures, joints cracks and cavities. These structural weak planes seriously hinder and affect the wave propagation in rock mass [4].

Rock mass is usually broken up by joints into rock elements, which are continuous and may be regarded as elastic bodies. The properties of rock mass are determined by the properties of the intact rock elements and geological conditions. The existence of rock joints affects not only significantly the properties of rock mass, but also their seismic response affects the design of underground structures [5].

In rock blasting, it is generally agreed that two types of loading operate on the surrounding rock; stress wave (shock wave) loading and explosion gas pressure loading. The stress wave loading arises out of detonation of the explosive column in the borehole. The high pressure on the borehole wall sets off a shock wave in the adjacent rock mass, but it soon decays to a high amplitude stress wave propagating at the velocity of longitudinal wave in the rock mass. It is immediately followed by the longer duration gas pressure loading. This loading due to gas expansion continues long after the stress wave has dissipated, as its expansion rate is considerably lower than that of the propagating stress waves. This action initiates cracks around the borehole, and then penetrates into cracks causing further extension and propagation [6].

When an explosion is produced, rock mass suffers from vibrations which depend on many factors. Some are easy to determine, as they are design factors and can be measured (e.g. burden, operating load, delay between shots, etc.), but other factors are very difficult to evaluate such as the clay stopper, the contact between the explosive and the hole walls, the existence of water in the hole and the heterogeneous nature of the rock mass [7].

Dynamic loads are usually associated with high amplitude and short duration. A proper understanding of the effect of loading rate on the mechanical properties of rocks is important in the analysis of rock behavior or the design of rock caverns subjected to dynamic loads. For example, in the event of an explosion in a cavern or under an external attack, shock waves are generated and propagate through the rock mass. The rock and rock structures at distances are 
subjected to shock loads at different loading rates. The amount of damage and instability that occurs to the rock and rock structures is highly dependent on the loading rate and is primarily governed by the dynamic strength properties of the rock [8].

Based on the above considerations, a field tests programme was conducted in Upper Egypt to study the ground blast pressure induced from explosions in the limestone formations covering large areas and currently exploited by many quarries.

\section{Site description}

The selected quarry for this experimental investigation is located in the mountainous region between Beni-Swif and Elmina, Egypt. In connection to the field tests, geological site investigations were carried out before the tests were conducted. It was found that the rock type at the site was limestone with relatively good quality. This area has different rock qualities due to the wide spread of rock joints, inclusion of shale layers and cavities as shown in Figure (1).

Unconfined compressive strength tests were carried out on some rock samples collected from the site. The average mechanical properties of intact rock are listed in Table (1).
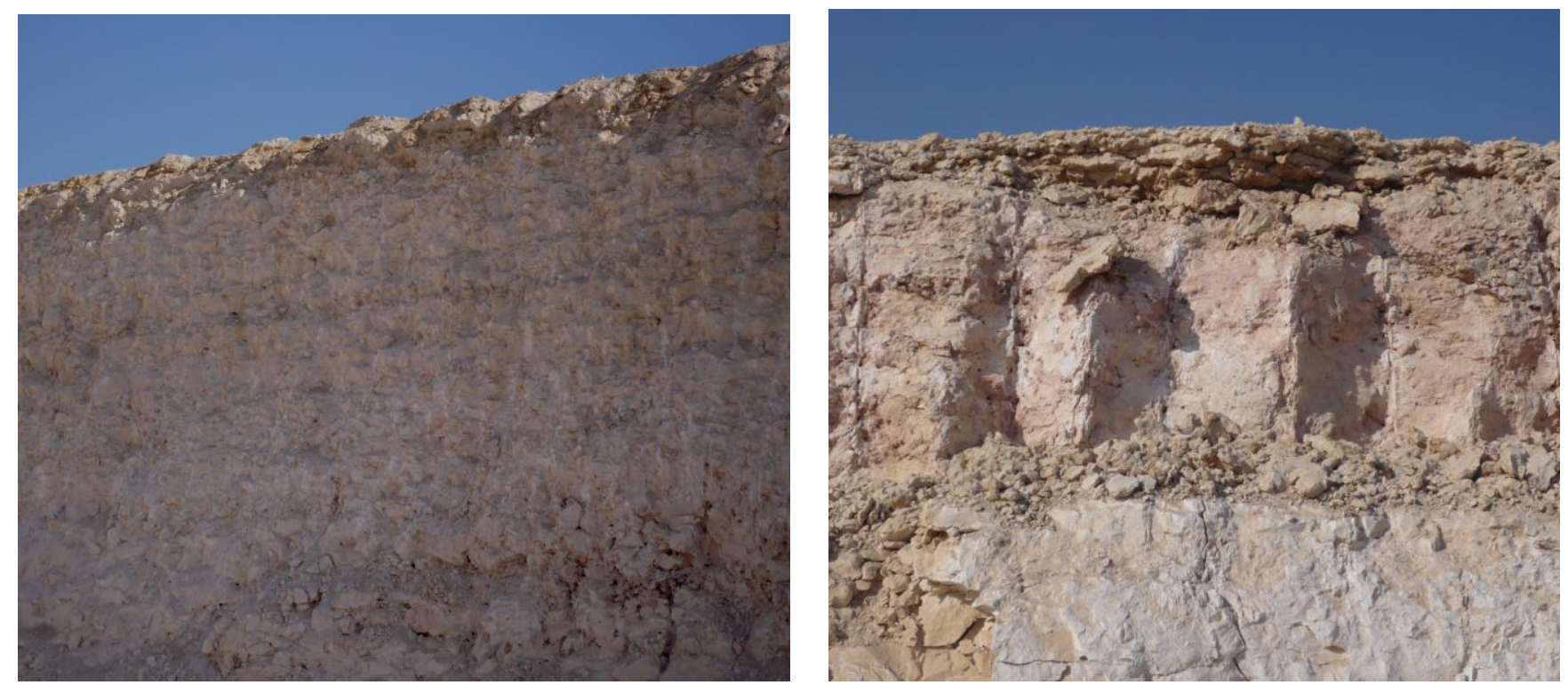

Figure: (1) Different geological view of the test sites 
Table (1): Average mechanical properties of intact rock

\begin{tabular}{|c|c|c|c|c|}
\hline $\begin{array}{c}\text { Young's } \\
\text { modulus } \\
\mathbf{M P a}\end{array}$ & $\begin{array}{c}\text { Uniaxial } \\
\text { compressive } \\
\text { strength } \\
\mathbf{M P a}\end{array}$ & $\begin{array}{c}\text { Tensile } \\
\text { strength } \\
\mathbf{M P a}\end{array}$ & $\begin{array}{c}\text { Unit } \\
\text { weight } \\
\mathbf{k N} / \mathbf{m}^{3}\end{array}$ & $\begin{array}{c}\text { Poisson's } \\
\text { ratio }\end{array}$ \\
\hline 250 & 25 & 2.5 & 26.5 & 0.3 \\
\hline
\end{tabular}

\section{Field test procedure}

\subsection{Measuring configuration and instrumentation}

Figure (2) presents the layout of the system configuration. The sensor was mounted into a steel disc to be protected from the explosion fragments and a steel tube was also used to protect the wires which transfer the signals to the data acquisition system, Figure (3) shows the field instrumentation devices setup.

The sensor interface PCD-30A is a voltage meter that is connected to the PC. It is capable of measuring voltage with ease using the control software. This system is capable of measuring through 4 channels per PCD-30A. Smart sensor PCB piezotronics was setup to record the incident pressure resulting from the explosion. The detected signals were amplified and then transmitted to the data acquisition system for recording. The manual measuring mode, sampling frequency of $1000 \mathrm{HZ}$ and maximum number of recording points of 10000 were setup to simultaneously record pressure wave histories as voltage sinusoidal wave to be calibrated by a special mathematical representation to translate the signals history curve into pressure-time history curve.

\subsection{Experimental programme}

The tests were performed with different charge weights, horizontal chargetarget distance and targets location below the ground surface. The selected variables of the field testing programme are summarized in Table (2). The four tests (test 1 to 4 ) were conducted using different weights of TNT charge. Vertical charge holes of $3 \mathrm{~m}$ in depth and about $0.1 \mathrm{~m}$ in diameter were drilled and the explosive charges (W1=6 kg \& W2 $=\mathrm{W} 3=\mathrm{W} 4=8 \mathrm{~kg}$ TNT) were placed inside the holes. The targets location was fixed at the same horizontal distance of $5 \mathrm{~m}$ from the charge center. The vertical location is directly under the ground surface for targets G1 and G2, and at a depth of about $1 \mathrm{~m}$ below the 
ground surface for targets $\mathrm{G}_{3}$ and $\mathrm{G}_{4}$ as illustrated in Figure (4). The field setup of targets sensor to be connected to the measuring devices is shown in Figure (5).

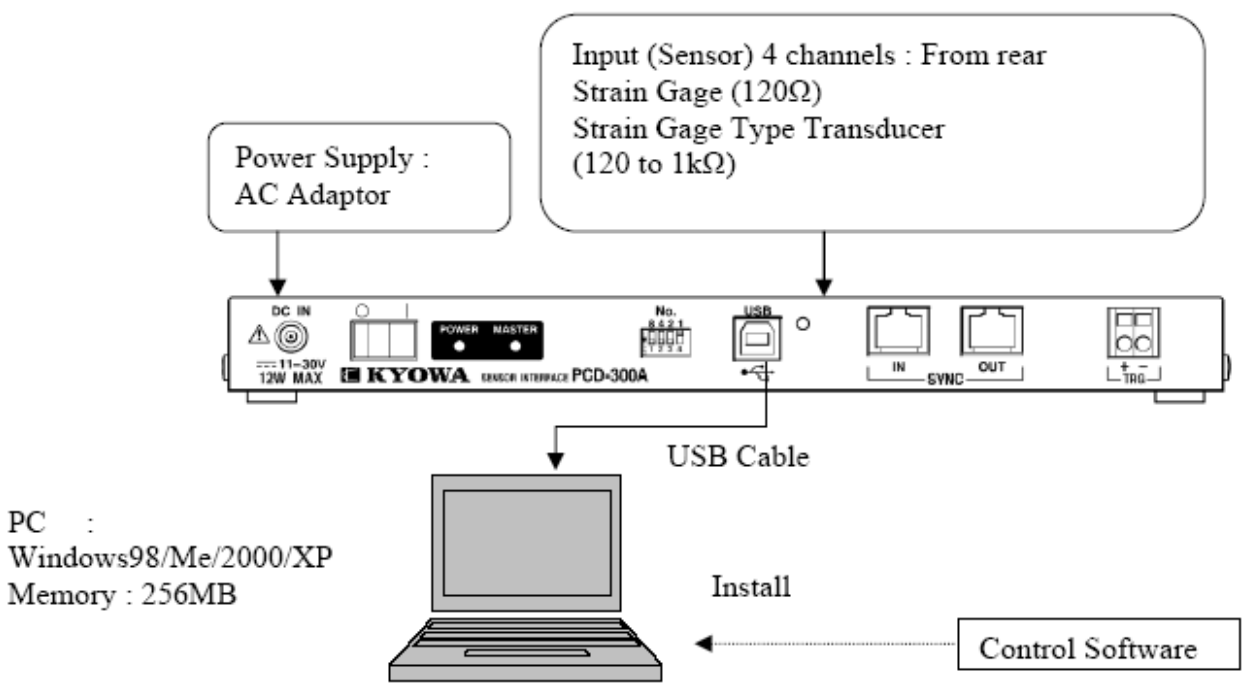

Figure (2): System configuration [9]
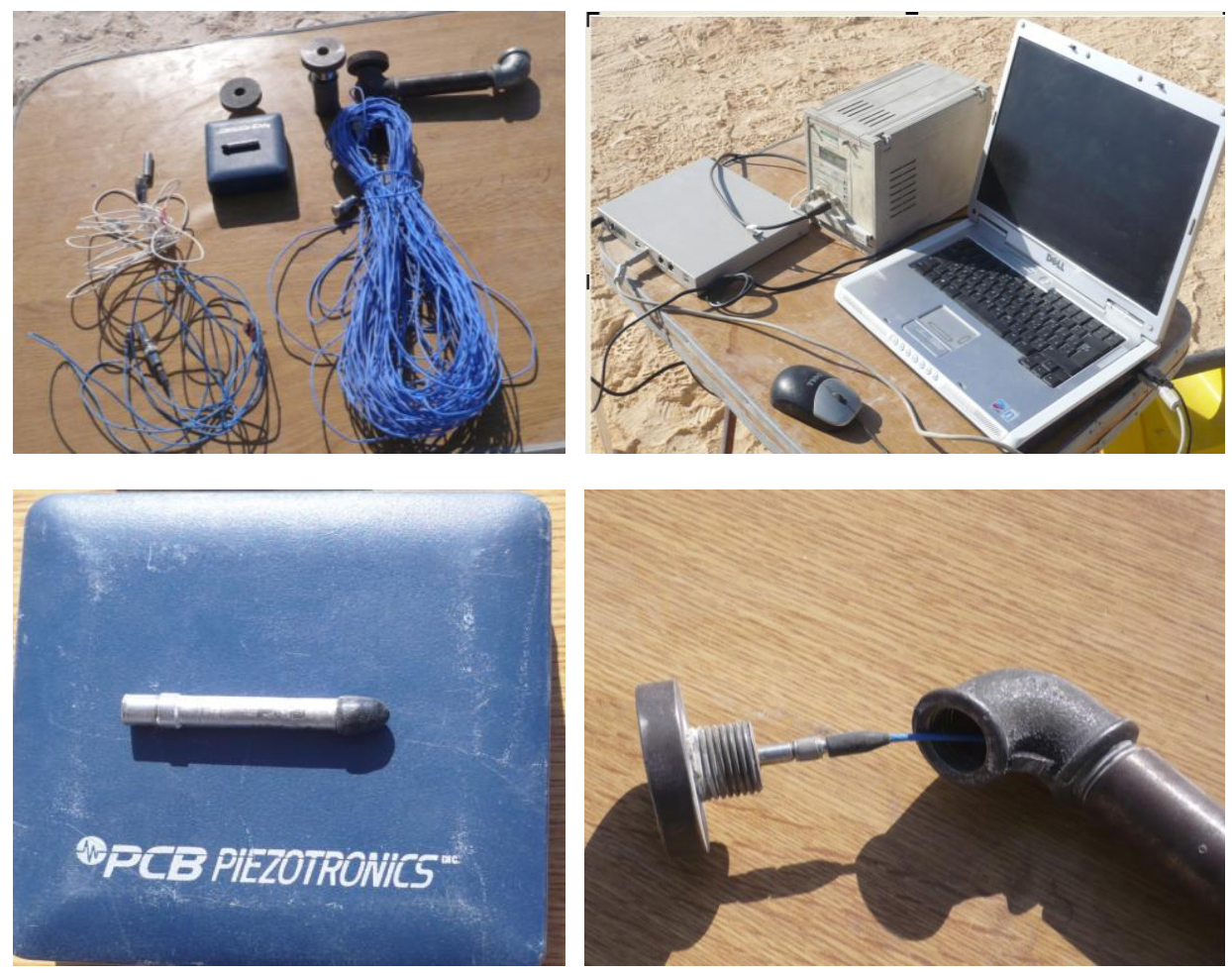

Figure (3): Field instrumentation devices setup 
Table (2): Selected variables of field tests

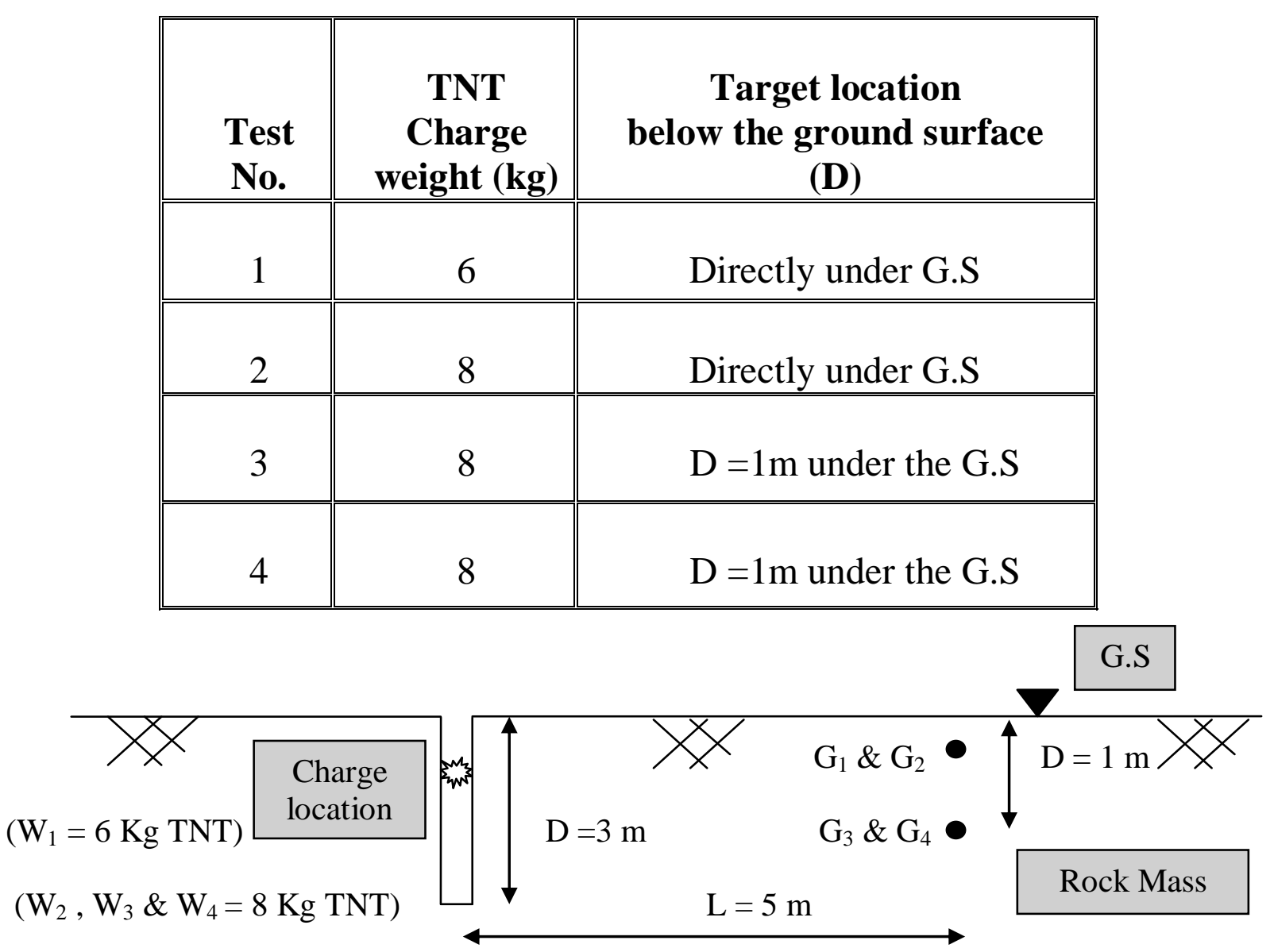

Figure (4): Layout of explosion tests
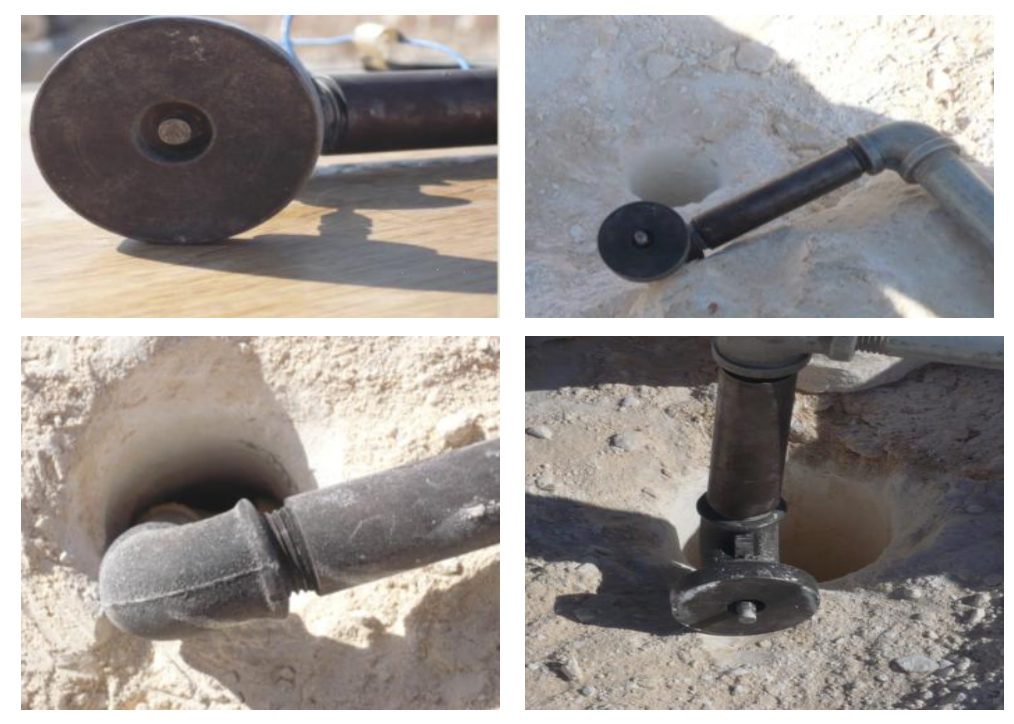

Figure (5): Field setup of the target sensor 


\section{Blasting results}

\subsection{Crater formation}

The response of the rock mass at the charge and target locations was examined and the incident pressure was recorded for the different conditions of the testing programme listed in Table (2).

The effect of the blasting action on the rock mass was monitored through the crater formation which is an appropriate tool to study the blast phenomena, the behavior and destructive power of different explosives and the response of rock mass under blasting load. A cavity is usually formed when an explosion is produced in a rock mass. The most important variables in defining the crater shape and size are the weight of the explosive and the depth of the detonation location [10]. Figure (6) shows the crater formation due to $6 \mathrm{~kg}$ TNT charge which was $2.3 \mathrm{~m}$ in diameter and $3.5 \mathrm{~m}$ in depth.

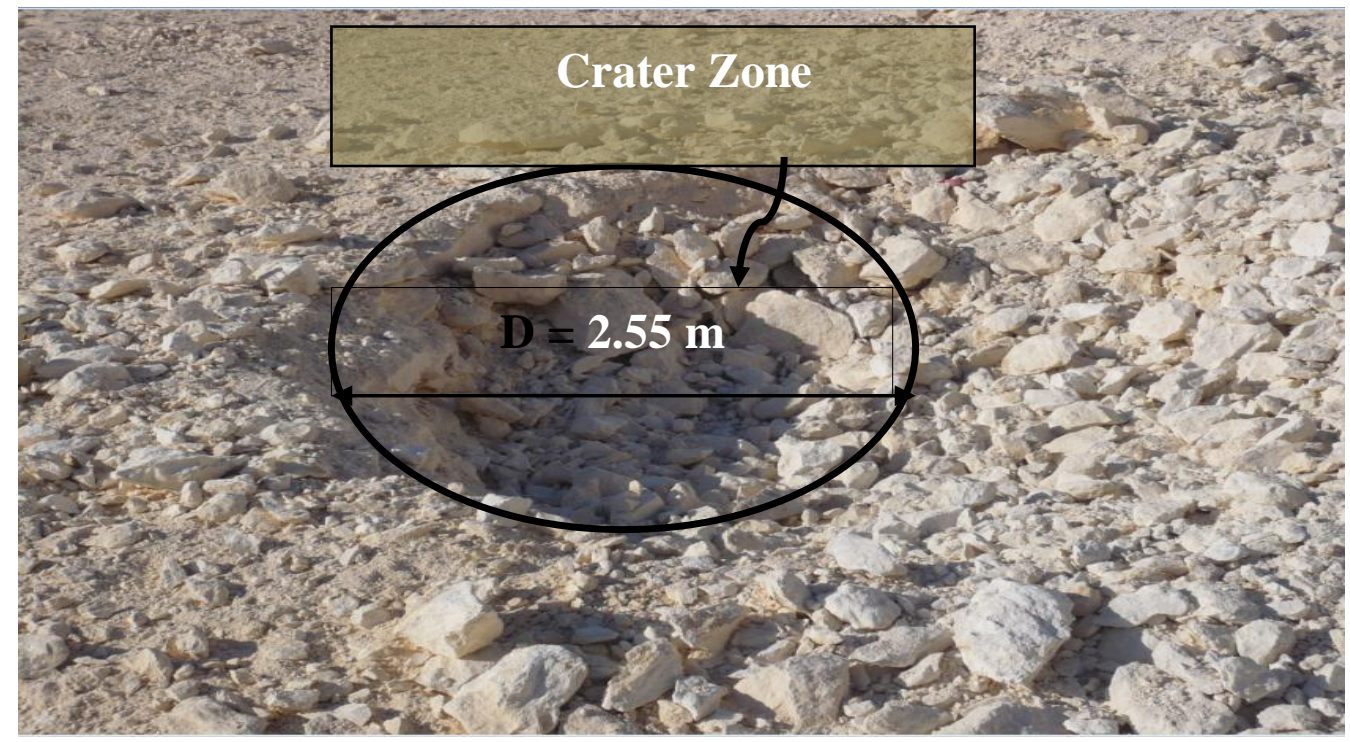

Figure (6): Crater formation

\subsection{Recorded incident pressure}

When an explosion occurs inside the rock mass, the peak incident pressure associated with the initial shock front will be extremely high and it will be amplified by their reflections within the rock mass. Depending upon the charge location, the effects of the high temperatures and accumulation of gaseous products produced by the chemical process involved in the explosion will exert additional pressures and increase the load duration within the rock mass. Figures (7, 8 and 9) show the incident pressure-time history according to the testing programme using the sensor interface PCD-30A.The values of maximum incident pressures and craters dimension are listed in Tables (3). 


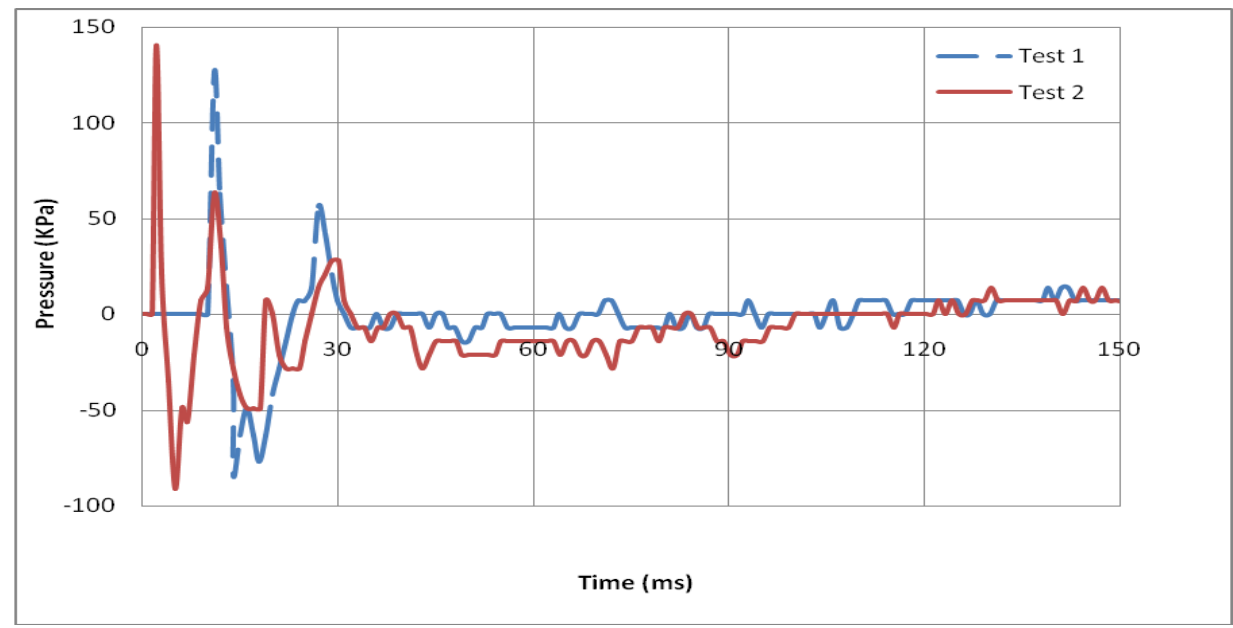

Figure (7): Pressure-Time history for recorded tests $(1 \& 2)$

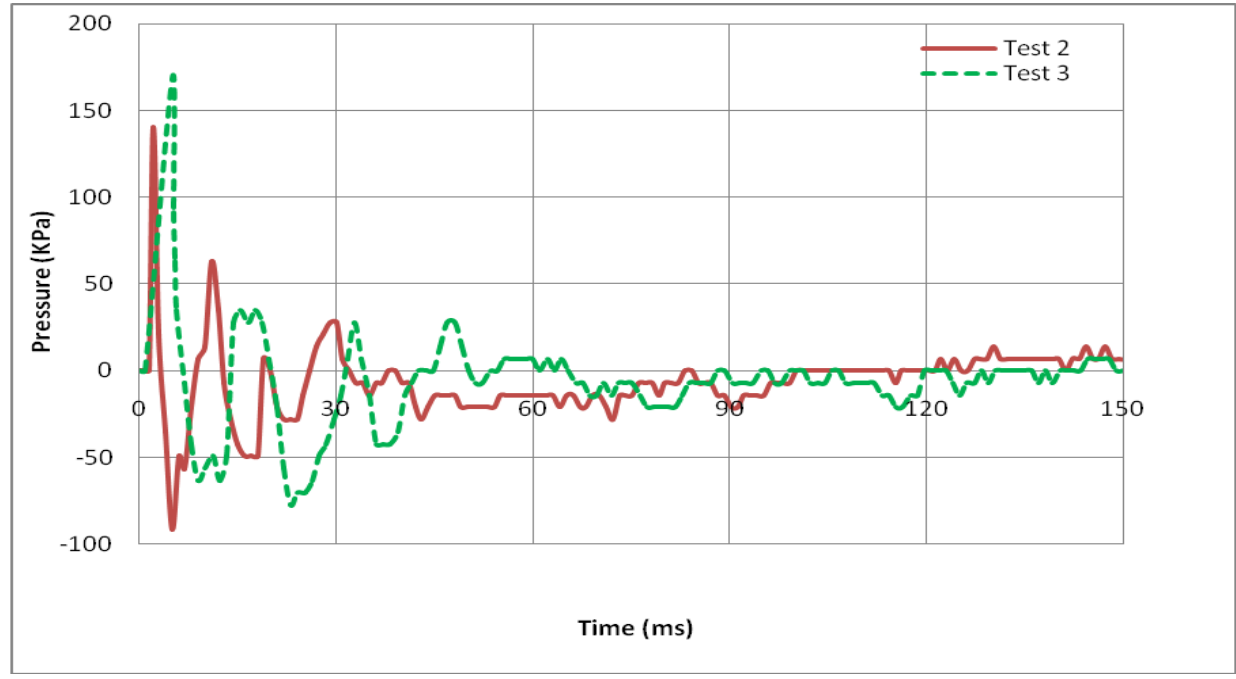

Figure (8): Pressure-Time history for recorded tests (2\&3)

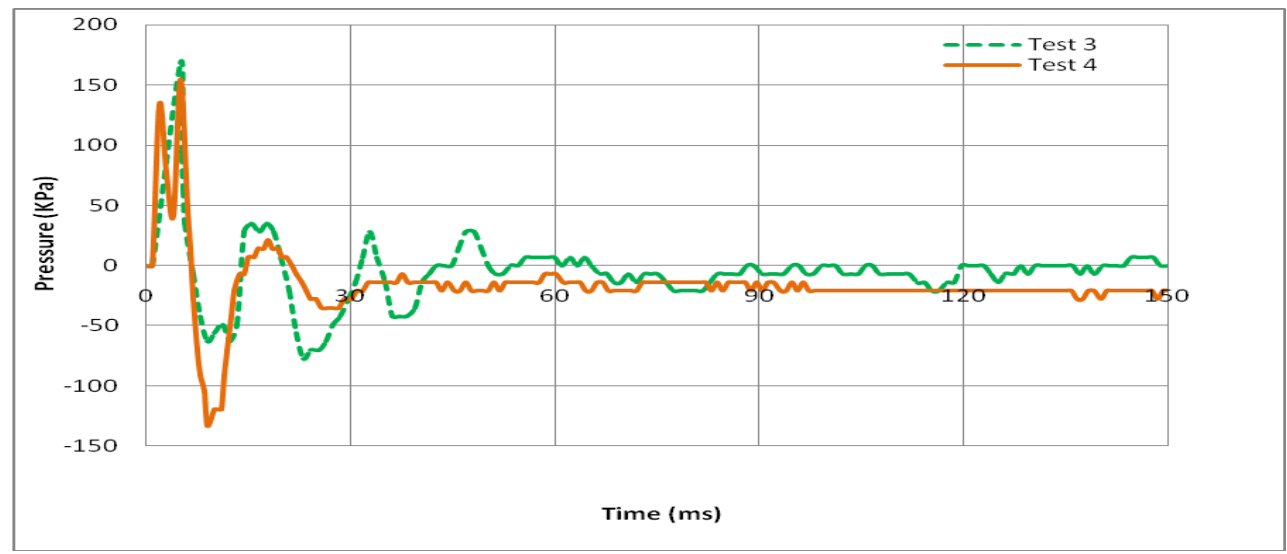

Figure (9): Pressure-Time history for recorded tests (3\&4) 
Table (3): Values of crater dimension and maximum incident pressure for explosion tests (1 to4)

\begin{tabular}{|c|c|c|c|c|}
\hline \multirow{2}{*}{$\begin{array}{l}\text { Test } \\
\text { No. }\end{array}$} & \multirow{2}{*}{$\begin{array}{c}\text { TNT } \\
\text { Charge } \\
\text { weight }(\mathrm{kg})\end{array}$} & \multicolumn{2}{|c|}{ Crater dimensions } & \multirow{2}{*}{$\begin{array}{l}\text { Max. incident } \\
\text { pressure } \\
(\mathbf{k P a})\end{array}$} \\
\hline & & $\begin{array}{c}\text { Diameter } \\
(\mathbf{m})\end{array}$ & $\begin{array}{c}\text { Depth } \\
(\mathbf{m}) \\
\end{array}$ & \\
\hline 1 & 6 & 2.3 & 3.5 & 126 \\
\hline 2 & 8 & 2.65 & 3 & 140 \\
\hline 3 & 8 & 2.55 & 2.7 & 168 \\
\hline 4 & 8 & 2.75 & 2.85 & 154 \\
\hline
\end{tabular}

\section{Discussion}

\subsection{Incident pressure value}

1. For the same target location, same geological conditions and different charge weights, the value of incident pressure depends on the charge weight. It can be noticed in tests $(1 \& 2)$ that the value of maximum incident pressure $\left(\mathrm{P}_{\max }=140\right.$ $\mathrm{kPa})$ on target $\left(\mathrm{G}_{2}\right)$ is greater than $\left(\mathrm{P}_{\max }=126 \mathrm{kPa}\right)$ on target $\left(\mathrm{G}_{1}\right)$, as shown in Figure (7).

2. For the same charge weight, same geological conditions and different in target location, it can be noticed in test $(2 \& 3)$ that the effect of depth on the detected incident pressure along the wave propagation perimeter $\left(\mathrm{P}_{\max }=168\right.$ $\mathrm{kPa})$ on target $\left(\mathrm{G}_{3}\right)$ is greater than $\left(\mathrm{P}_{\max }=140 \mathrm{kPa}\right)$ on target $\left(\mathrm{G}_{2}\right)$, as shown in Figure (8).

\subsection{Effect of Geotechnical Conditions on Wave Propagation}

The two targets $\mathrm{G}_{3} \& \mathrm{G}_{4}$ were located at the same depth from the ground surface $(\mathrm{D}=1 \mathrm{~m})$ in two different sites and using the same charge weight $(\mathrm{W}=8 \mathrm{~kg})$. It is found that the value of maximum incident pressure $\left(\mathrm{P}_{\max }=168 \mathrm{kPa}\right)$ on target 
$\left(\mathrm{G}_{3}\right)$ is greater than $\left(\mathrm{P}_{\max }=154 \mathrm{kPa}\right)$ on target $\left(\mathrm{G}_{4}\right)$ due to the different geological conditions for the two sites. It is noticed from Figure (9), the value of the initial shock front wave on target $\left(\mathrm{G}_{4}\right)$ is $(\mathrm{P}=133 \mathrm{kPa})$ and it was amplified to the value of $\left(\mathrm{P}_{\max }=154 \mathrm{kPa}\right)$ by its reflection within the rock mass as a result of the change in continuity of rock mass. The rock mass often contains one or more sets of discontinuities, including bedding planes, joints, and cleavages. These discontinuities, of course, participate in the global deformational behavior of the rock mass. In-situ tests and laboratory physical model tests have revealed that the presence of joints reduces the strength and deformation modulus of intact rock into those of rock masses. The degrees of these reductions are governed by factors such as joint configuration and the mechanical properties of the intact rock and the joints. However, it helps for the mitigation of the wave propagation.

\section{Conclusions}

A series of field experiments were conducted to investigate the effect of different variables such as, charge weight, horizontal charge-target distance and target location below the ground surface and to study the effect of blast wave propagation within a rock mass due to explosions. The results indicated that:-

1- The maximum incident pressure on the rock mass depends on the charge weight, continuity of the rock mass and the location of concerned measured point.

2- Investigation of the geological condition of affected rock mass is very essential before field test performance to get a logical explanation of the recorded data.

3- Rock mass joints and cavities have a significant effect on blast-induced shock wave propagation by scattering it faraway from the structures.

4- Crater formation is an appropriate parameter to estimate the quality of the rock mass and its dynamic response to explosion just below the ground surface or at deeper levels.

\section{$\underline{\text { 7. Acknowledgement }}$}

I am deeply grateful to Prof. Dr. Fathalla El-Nahhas, Professor of Geotechnical Engineering, Faculty of Engineering, Ain Shams University, for his inspiration, encouragement and sincere advice which greatly contributed to the research. 


\section{$\underline{\text { 8. References }}$}

[1] C. Wu, H. Hao, Y. Lu, "Dynamic Response and Damage Analysis of Structures and Masonry Infilled RC Frames to Blast Ground Motion" Engineering Structures, Vol.27, pp. 323-333, 2005.

[2] Y.O. Zhang, H. Hao, Y. Lu, "Anisotropic Dynamic Damage and Fragmentation OF Rock Materials under Explosives Loading" International Journal of Engineering Science, Vol.41, pp. 917-929, 2003.

[3] J. P. Latham, P. Lu, "Development of an Assessment System for the Blastability of Rock", Int. J. Rock Mech. and Mining Science Vol. 36, pp.41-55, 1999.

[4] W. Wei, L. Xi, Z. Yu, Z. Zi, Z. Zhang, "3 DEC Modelling on Effect of Joints and Interlayer on Wave Propagation" Transactions of non-Ferrous Metals Society of China Vol. 16, pp.728-734, 2006.

[5] Y. K. Wu., H. Hao., Y.X. Zhou, and K. Chong, "Propagation Characteristics of Blast Induced Shock Waves in a Jointed Rock Mass" Soil Dynamics and Earthquake Engineering, Vol.17, pp. 407-412, 1998.

[6] Z. Zhu, B. Mohanty, H. Xie, "Numerical Simulation of Blasting-Induced Crack Initiation and Propagation in Rocks" Int. J. Rock Mech. and Mining Science, Vol.44, pp. 412- 424, 2007.

[7] J.TORANO, P. RAMIREZ, R. RODRIGUEZ, I. DIEGO, "Analysis of Environmental Effects of Ground Vibrations Produced by Blasting in Quarreis " Int. J. of Mining Reclamation and Environment, Vol.20, No. 4, pp. 249- 266, 2006.

[8] J. Zhao, Y. X. Zhou, A. M. Hefny, "Rock Dynamics Research Related to Cavern Development for Ammunition Storage", Tunnelling and Underground Spate Technology, Vol. 14, No. 4, pp. 513-526, 1999.

[9] KYOWA Electronic Instruments CO. LTD, Instruction Manual, Japan.

[10] B. Luccioni, D. Ambrosini, G. Nurick and I. Snyman, "Craters Produced by Underground Explosions", Computer and Structures, Vol. 87, pp.13661373, 2009. 